chromium (CrR, $\mathrm{CrU})$, and chromium in whole blood and in erythrocytes (CrBl, CrEry) in welders.

Methods Respirable welding fume was collected in 241 welders during a working shift. Blood samples and spot urine samples were collected after the working shift. The content of CrR in the welding fume was determined using inductively coupled plasma mass spectrometry. $\mathrm{CrU}, \mathrm{CrBl}$ and CrEry were measured by means of graphite furnace atom absorption spectrometry. Linear regression models were applied to model exposure to chromium. A multiple imputation approach was chosen to account for values below the limit of quantitation (LOQ).

Results Median concentrations of CrR were $<3.80 \mu \mathrm{g} / \mathrm{m}^{3}$, with about 23\% below LOQ. Major determinants of the CrR were the chromium content in the electrodes or base material in addition to the type of welding. Airborne exposure was higher when welding was performed under inefficient ventilation. CrR correlated strongly with $\mathrm{CrU}$ (Pearson's correlation $\mathrm{r}=0.61$ ). Median concentrations of $\mathrm{CrU}$ were $<1.20 \mu \mathrm{g} / \mathrm{m}^{3}$, and $44 \%$ of $\mathrm{CrU}$ measurements were below LOQ. CrU exposure decreased by a factor of 0.66 when a respiratory mask was used. Most measurements of $\mathrm{CrBl}$ and CrEry were below LOQ. All 15 welders with a measurable concentration of CrEry had high chromium contents in the materials (above 5\%).

Conclusions CrR was mainly influenced by the chromium content in the materials and the welding process. Welding in confined space increased exposure to CrR. Efficient local exhaust ventilation and the use of respirators decreased exposure. Airborne $\mathrm{Cr}$ concentration was a good predictor of urinary $\mathrm{Cr}$ exposure.

\section{AIR MEASUREMENTS OF BENZENE AND OTHER ORGANIC COMPOUNDS IN THE NORWEGIAN PETROLEUM INDUSTRY 2007-2009: A REVIEW OF INDUSTRIAL HYGIENE REPORTS}

B B Bakke. National Institute of Occupational Health, Oslo, Norway

\subsection{6/oemed-2013-101717.236}

Objective Description of current exposure levels of benzene and other organic compounds among workers in the petroleum industry.

Materials A total of 2578 air measurements taken by 12 oil and service companies were evaluated and summarised in a database. The data includes personal full-shift samples and measurements on specific tasks.

Results Most samples were from offshore installations (70\%). 93 chemical agents were detected in the samples. Of these, 11 agents were measured in 100 or more samples including aromatic hydrocarbons (benzene $n=853$, toluene $n=1014$, xylene isomers $n=987$, and ethylbenzene $n=939$ ) and alkanes ( $n$-hexane $n=856$, oil vapour $n=130$, oil mist $n=132$ ). $66 \%$ of the chemical agents were measured in less than 11 samples. In total, 299 work tasks were described in the reports.

Generally, personal exposure levels of full-shift samples of benzene $($ median $=0.005 \mathrm{ppm})$, toluene $($ median $=0.005$ $\mathrm{ppm}$ ), ethylbenzene (median $=0.001 \mathrm{ppm})$, xylene (all isomers) $($ median $=0.005)$, and $n$-hexane $($ median $=0.003)$ were low compared to Norwegian 12-hour time-weighted average occupational exposure limits of $0.6 \mathrm{ppm}, 15 \mathrm{ppm}, 3 \mathrm{ppm}, 15 \mathrm{ppm}$, and 12 ppm, respectively.

The highest personal air levels were reported when performing tasks such as cleaning of tanks, opening of processing units, changing of filters, and sampling from the petroleum stream.
Conclusion Although much of the monitoring data has been conducted for control evaluation and compliance, they provide a basis for industrial hygienists and exposure assessors to identify work tasks and jobs where exposures are likely, and provide an overview of current exposure levels. This work also shows that for most agents the exposure data is extremely sparse and therefore there is a need to measure chemical exposures in this industry.

\section{THE WHAT-ME STUDY: RELATIONSHIPS BETWEEN WORK PRACTICES AND URINARY METAL CONCENTRATIONS AMONG WOMEN WORKING IN NON-TRADITIONAL TRADES}

${ }^{1} \mathrm{H}$ Arrandale, ${ }^{2}$ Manning, ${ }^{1}$ Beach, ${ }^{1} \mathrm{M}$ Cherry. ${ }^{1}$ University of Alberta, Edmonton, Canada; ${ }^{2}$ Northern Alberta Institute of Technology, Edmonton, Canada

\subsection{6/oemed-2013-101717.237}

Objectives The WHAT-ME cohort is a prospective study of reproductive health among Canadian women in non-traditional trades. The goal of this sub-study was to investigate associations between the exposure questionnaire and urinary metal concentrations.

Methods Women registered in welding, boilermaking, steam fitting/pipefitting ('welders') or electrical trade apprenticeships since 2005 were invited to join the cohort. Participants in the Alberta sub-study mailed-in a urine sample at 6 months. Correlations between urinary metals (by ICP MS) were investigated and principal components extracted. Relationships between individual metals, component scores and work practices (from exposure questionnaires at 6 months) were investigated.

Results 183 urine samples were collected. Analysis was limited to 108 subjects (57 welders, 51 electricians) who had completed trade-specific work since enrolment. Smokers (38\%) had significantly higher urinary concentrations of cadmium, cobalt and lead. Metal concentrations were more strongly correlated in welders than electricians. In welders, the first principal component explained $46 \%$ of the variability in metal concentrations but for electricians only $23 \%$. Geometric mean of each of the 12 metals measured was higher for welders than electricians: only chromium reached significance $(0.51$ vs. $0.16 \mathrm{ug} / \mathrm{g}$-creatinine, $\mathrm{p}<0.001)$. Among welders, tungsten inert gas (TIG) welders tended to have lower metal concentrations while those doing manual metal arc welding had significantly higher zinc concentrations $(\mathrm{p}<0.05)$. Preliminary analyses of work practices suggest that both personal protective equipment and local exhaust ventilation were related to urinary metal concentrations; supplementary analyses will also include data on consumables and base metals.

Conclusions Urinary metal concentrations tended to be higher and more strongly correlated among welders compared with electricians. Welding tasks, materials and controls associated with urinary metal concentrations will guide strategies for exposure reduction in the welding trade.

\section{STATISTICAL MODELLING OF PM10 AND PM2.5 EXPOSURES IN POULTRY BARNS, AND EVALUATION OF ELECTROSTATIC PRECIPITATORS TO CONTROL PARTICULATE EMISSIONS}

L Kirkham, Lavoué. University of Montreal, Montreal, Canada

\subsection{6/oemed-2013-101717.238}

Objectives Particulate concentrations within poultry barns pose a potential occupational and environmental health concern. We 